\title{
USING FORMATIVE RESEARCH TO DEVELOP A CONTEXT- SPECIFIC APPROACH TO INFORMED CONSENT FOR CLINICAL TRIALS
}

\author{
Amy L. Corneli, \\ University of North Carolina at Chapel Hill \\ Margaret E. Bentley, \\ University of North Carolina at Chapel Hill \\ James R. Sorenson, \\ University of North Carolina at Chapel Hill \\ Gail E. Henderson, \\ University of North Carolina at Chapel Hill \\ Charles van der Horst, \\ University of North Carolina at Chapel Hill \\ Agnes Moses, \\ The UNC Project, Lilongwe, Malawi \\ Jacqueline Nkhoma, \\ The UNC Project, Lilongwe, Malawi \\ Lyson Tenthani, \\ Independent Consultant, Lilongwe, Malawi \\ Yusuf Ahmed, \\ Centers for Disease Control and Prevention, Atlanta \\ Charles M. Heilig, and \\ Centers for Disease Control and Prevention, Atlanta \\ Denise J. Jamieson \\ Centers for Disease Control and Prevention, Atlanta
}

\section{Abstract}

Participant understanding is of particular concern when obtaining informed consent.

Recommendations for improving understanding include disclosing information using culturally appropriate and innovative approaches. To increase the effectiveness of the consent process for a clinical trial in Malawi on interventions to prevent mother-to-child transmission of HIV during breastfeeding, formative research was conducted to explore the community's understanding of medical research as well as how to explain research through local terms and meanings. Contextual analogies and other approaches were identified to explain consent information. Guided by theory, strategies for developing culturally appropriate interventions, and recommendations from the literature, we demonstrate how the formative data were used to develop culturally appropriate 
counseling cards specifically for the trial in Malawi. With appropriate contextual modifications, the steps outlined here could be applied in other clinical trials conducted elsewhere, as well as in other types of research.

\section{Keywords}

Formative research; informed consent; theory; culturally appropriate; HIV/AIDS

International guidelines and many local regulations clearly state that potential participants must understand consent information before consenting to participate in research (DHHS, 1991; Nuremberg Code, 1949; World Health Organization (WHO)/Council for International Organizations of Medical Sciences (CIOMS), 2002; World Medical Association (WMA), 2000).

Ensuring that participants understand this information, however, can be a challenge. With exceptions (Pace et al., 2005), the few empirical research studies of informed consent in resource-limited countries have demonstrated inadequate participant understanding of many fundamental research concepts (Ekouevi et al, 2004; Leach et al., 1999; Lynöe et al., 2001; Molyneux et al., 2004). Several studies conducted in North America and Europe have also reported similar findings (Advisory Committee on Human Radiation Experiments (ACHRE), 1995; Daugherty et al., 1995; Joffe et al., 2001; Riecken and Ravich, 1982). Review articles have identified numerous studies that have evaluated alternative approaches for improving participant understanding (Agre et al., 2003; Dunn \& Jeste, 2001; Edwards et al., 1998; Flory \& Emanuel, 2004). Only a few studies, however, have been carried out in resource-limited countries (Fitzgerald et al., 2002; Préziosi et al., 1997). Information on effective methods for improving participant understanding in these settings is therefore very limited.

Recommendations have been made for improving understanding of consent information among participants in resource-limited countries. In 2001, the National Bioethics Advisory Committee (NBAC) suggested including members of the local community in the design of the consent process and disclosing information through culturally appropriate and innovative ways. Woodsong and Abdool Karim (2005) proposed a conceptual framework for ensuring initial and continued participant understanding of research. Among other suggestions, the importance of community involvement and appropriateness of consent materials is emphasized. Few step-by-step or "how-to" guidelines exist, however, for incorporating recommendations for improving participant understanding into the design of consent information.

Here we present steps taken to develop a context-specific consent approach that was evaluated for the Breastfeeding, Antiretroviral, and Nutrition (BAN) study. The BAN study is a clinical trial in Lilongwe, Malawi, on the safety and efficacy of interventions to prevent mother-to-child transmission of HIV during breastfeeding (Gaillard et al., 2004; van der Horst et al., 2003). Objectives of the clinical trial include evaluating the benefit of nutritional supplementation given to mothers during breastfeeding, the benefit and safety of antiretroviral medications given either to infants or their mothers to prevent HIV transmission during breastfeeding, and the feasibility of exclusive breastfeeding followed by early, rapid breastfeeding cessation. The study has a randomized 2-by-3 factorial design where mothers receive or do not receive a daily nutritional supplement, and mothers, infants, or neither receives daily antiretroviral prophylaxis for 24 to 28 weeks during the breastfeeding period (Figure 1). Healthy breastfeeding mothers who do not meet HIVtreatment eligibility criteria (i.e., with a CD4 t-cell count $>200$ cells $/ \mu \mathrm{L}$ ) and are not severely 
anemic (i.e., have hemoglobin $\geq 7 \mathrm{~g} / \mathrm{dL}$ ) and their HIV-negative newborns are eligible to enroll1.

Our context-specific consent approach was guided by a framework by Kreuter et al. (2003) for designing culturally appropriate health promotion interventions. The framework includes five categories: peripheral, evidential, linguistic, constituent, and sociocultural strategies. Peripheral strategies make interventions appear familiar to the target population by using recognizable images, evidential strategies incorporate epidemiological findings into interventions, and linguistic strategies focus on providing messages in the local language. Constituent strategies encourage the inclusion of members of the target audience or cultural group in the design of interventions, and sociocultural strategies integrate broad cultural and social beliefs into the intervention as a way to make it culturally meaningful.

As participant understanding of consent information is an educational process, educational theory also informed the content of our consent approach. Specifically, of the cognitive learning methods, receptive learning is the primary method involved in understanding the information presented during the consent process. In receptive learning, information is provided to the recipient in its entirety; no active discovery learning such as problem solving is needed. As theorized, the recipient then understands the information and internalizes it for later use and related learning (Ausubel, 1968). According to a theory of receptive learning called the Assimilation Theory of Meaningful Learning, new knowledge can be meaningful to learners, and thus understood and retained, when it is related to existing knowledge (Ausubel, 1963; Ausubel, 2000). In our consent approach, contextual analogies were used to explain research concepts, as analogies are one of many methods used to associate new knowledge with existing knowledge (Reigeluth, 1983). In addition, previous research has shown increased understanding of information presented using analogies (Newby et al., 1995).

Not only did our intervention focus on disclosing consent information in culturally appropriate ways, but we also chose to present the information by developing a culturally appropriate method: counseling cards. Previously used in Lilongwe to provide education on family planning, counseling cards are a familiar method for providing health information. Counseling cards, also known as flip charts, are increasingly being used to administer consent information (Creed-Kanashiro et al., 2005; Jamieson et al., 2003; Woodsong et al., 2004). Consent information is written on one side of the cards for the nurse to read to the potential study participant. While the nurse reads the information aloud, the participant views drawings that visually describe the information she is hearing from the nurse. Drawings were also included in our approach because previous studies have reported that text simplification combined with drawings to explain key concepts has improved participant understanding of consent information (Murphy et al. 1999).

Development of the text for the counseling cards began with the conduct of formative research, a method commonly used to inform interventions (Cortes et al., 2001; CreedKanashiro et al., 2003) including consent information (Jimison et al., 1998; Murphy et al., 1999; Peduzzi et al., 2002). Topics explored during the formative research were informed by data from an earlier formative study we conducted. Data from this first formative study, which is reported in detail elsewhere (Corneli et al., 2007), suggested that the community had limited understanding of research such that they believed all medicines provided would already have been tested and known to be safe and efficacious; participants would be

\footnotetext{
${ }^{1} \mathrm{CD} 4$ cells are lymphocytes which are infected by HIV. A normal CD4 count would be greater than 500 cells per microliter (cells/ $\mu \mathrm{L}$ ). The CDC and WHO definition of AIDS would be a CD4 $\geq 200$ cells. A normal hemoglobin for a pregnant woman in a developed country is $\geq 11$ grams per deciliter ( $\mathrm{g} / \mathrm{dL}$ ). Below $7 \mathrm{~g} / \mathrm{dL}$ would be considered severely anemic.
} 
assigned to a study condition on the basis of their individual health needs, not by chance; and the clinical trial was designed to benefit the participants. The purpose of the second formative study was to explore participant understanding of medical research in more detail and to determine how to explain consent information more effectively. Through the review of the data from the second formative study, a team composed of U.S. and Malawian investigators identified areas of limited and sufficient understanding of medical research, as well as contextual analogies and other approaches to explain consent information. Additionally, based on the formative data and clinical trial procedures, scenes for the counseling cards were conceptualized and a local artist then created the drawings. In this paper, we detail each of these steps, beginning with the formative research.

The research was approved by the institutional review boards at the Centers for Disease Control and Prevention, the University of North Carolina at Chapel Hill (UNC), and the National Health Science Research Committee in Malawi. All participants gave their written informed consent.

\section{Formative Research Methods PARTICIPANTS AND RESEARCH TOPICS}

Guided by rapid assessment methods (Bentley et al., 1988; Scrimshaw \& Gleason, 1992), we conducted a qualitative descriptive study to develop the context-specific text for the counseling cards. Multiple qualitative methods and several key informants were involved in the formative research. Semi-structured interviews were conducted with 20 Malawian women infected with HIV who had an infant less than 1 year of age, including 12 women who had previously participated in research. Ages of women ranged from 18 to 36 , and education ranged from no schooling to completion of secondary school (12 years). Descriptive information about the BAN study as well as several of the basic elements of informed consent as defined in United States federal regulations (DHHS, 1991) were provided and we explored the women's overall perception of medical research, their willingness to participate in research to assess the safety and efficacy of medicine, and the social context in which research participation decisions were made.

Because understanding consent information is an educational process, we also conducted semi-structured interviews with 11 Malawian teachers (5 primary school, 5 secondary school, 1 adult literacy). Their teaching experience ranged from 8 to 10 years, and we explored how to explain research concepts and study procedures to Malawian women based on local teaching methods, including the use of analogies. Unstructured interviews were conducted with 8 Malawian research nurses to learn from their past experiences in administering the consent process, including their perceptions of the barriers leading to limited participant understanding of consent information and how best to explain the information. In addition, as a method to contextualize barriers to the consent process identified in previous studies (Henley et al., 1995; Marshall, 2001), nurses sorted cards listing pre-identified barriers into piles of "perceived barriers" or "not perceived barriers", and each pile was discussed in detail. Nurses had 10 months to 5 years of experience as research nurses, and all eight had previously been responsible for administering the consent process. Furthermore, because research is conducted within communities, we conducted 5 focus group discussions with community leaders and members of the Community Advisory Board (CAB). Using vignettes that described fictional characters (Hughes \& Huby, 2002), including an HIV-positive woman named Abigail, we explored community perceptions and norms regarding medical research and the BAN study from the perspectives of both the characters and the participants (see Figure 2). Of the three gender-specific focus group discussions with community leaders, one was conducted with female community leaders and two with male community leaders; both women and men participated in the two focus group 
discussions with $\mathrm{CAB}$ members. Lastly, in the interviews and focus group discussions we explored the translation of several key English words into Chichewa, the local language, such as "research," "medicine," "risk," and "chance," as frequently the direct translation of English words into a local language is not possible. Moreover, previous research has demonstrated that some languages use a single word for both "research" and "medicine" (Kass \& Hyder, 2001), which can complicate participant understanding of these terms.

\section{SAMPLING AND RECRUITMENT}

Non-probability, purposeful sampling techniques were used (Patton, 2002). Headmasters identified teachers from numerous public schools within the various administrative units in Lilongwe; BAN study nurses identified nurses with previous research experience, including themselves; and clinic nurses and a local AIDS support organization recruited women infected with HIV, of whom several were recruited because of their previous participation in research. Community leaders were identified by BAN nurses and recruited from catchment areas in three local health centers in which recruitment for the BAN study would occur. All members of the $\mathrm{CAB}$ were invited to participate in the focus group discussions, and participation was self-selected.

\section{DATA COLLECTION}

Five trained Malawian field investigators conducted all interviews and focus group discussions except for the unstructured interviews with research nurses, which were conducted by the field coordinator (primary author). Before data collection, the field coordinator reviewed each vignette and question with the field investigators to ensure that the underlying meanings were understood. Next, to translate the guides into Chichewa, the field investigators worked in groups and decided upon the most appropriate Chichewa words, terms, and context to use to convey the meaning of all narrative statements and questions. After translation into Chichewa was completed, the field investigators verbally back-translated all narrative statements and questions into English to the field coordinator to ensure that meaning was maintained after translation; modifications were made as necessary. English and Chichewa are the official languages of Malawi, and all field investigators were bilingual.

All interviews and focus group discussions were audio-taped and then simultaneously transcribed and translated verbatim into English by the field investigator who conducted the interview or focus group discussion. As findings were to be reported in another language from that in which the data were generated, numerous consultations were made throughout the data collection period between the field coordinator and field investigators, as suggested by Birbili (2000), to ensure that all Malawi-specific meanings, expressions, and terms were understood. Interviews, which lasted between 1 and $1 \frac{1}{2}$ hours, were conducted in a private

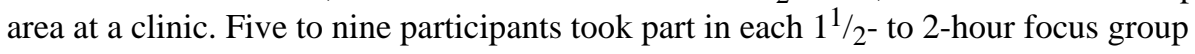
discussion, and all discussions were conducted in a private area at a clinic or at the UNC Project office.

\section{DATA ANALYSIS}

Qualitative content analysis was used to analyze the data, and analytical techniques described by Miles and Huberman (1994) and Sandelowski (1995) guided the analysis. After transcription and translation using a comprehensive preparation and transcription protocol (McLellan et al., 2003), the verbatim transcripts were read for content to ensure we were obtaining rich, detailed answers. Next, each transcript was reviewed individually with each field investigator to ask any questions about the data that were unclear and to suggest additional areas to explore based on emerging themes. After rereading the transcripts to become familiar with the perspectives of each participant, the primary author created 
inductive codes and codes based on the research questions. The interview text was then electronically coded using QSR NUD*IST Vivo software, and coding reports were examined for themes across the interviews. The most essential points were discussed among the team and summarized, and included areas of both limited and sufficient understanding of research concepts and study procedures, local terms and meanings to best explain these topics, issues surrounding participation in a safety and efficacy trial, and voluntariness.

\section{Formative Findings}

Data presented here focus on several aspects of participant understanding of consent information to demonstrate how the formative findings were used to develop counseling cards to administer the consent process.

\section{UNDERSTANDING OF MEDICAL CARE AND MEDICAL RESEARCH}

Compared to some languages, separate Chichewa words exist for "research" and "medicine." Derived from the verb "to investigate," "research" is translated as "kafukufuku" and is defined as "trying to find out something." In contrast, medicine, as in drugs, is translated as "mankhwala" and the field of medicine is translated as "za chipatala." In addition, different Chichewa terms exist for medical research and medical care: medical research is "kafukufuku wa mankhwala" and medical care is "chithandizo chaku chipatala." Yet, HIV-positive women's perceptions of medical care and medical research were similar. For example, one woman who described the purpose of medical care as "When you have a problem you go to the hospital where they assist you ... they examine you and then give you medication" (married woman, age 27, S52) had an analogous explanation of medical research: "In research they examine you so they can find out exactly what is happening in your body and therefore they can give you medicine that can be of some help." Another woman described medical care as, "The way I think about medical help, when a person is sick, he is taken care of. He is provided with medicine and the medical personnel make sure that the patient is assisted" (married woman, age 20, F2). When asked what she would expect if she participated in the BAN study, she said, "I would anticipate to be assisted. Since my infant will be provided with the drugs, I would expect him to grow healthy." Perceptions among mothers of a therapeutic benefit for infants, such as the preceding narrative, were not uncommon. Repeatedly, mothers said "infants would be safe since they will now not get HIV" (married woman, age 25, F4). Similarly, one nurse said, "The concept of research is a new thing. People are not used to research. So when women go to the hospital, they think the medicine they receive is treating something, not necessarily a trial [experiment]" (female nurse, 10 months as research nurse, 8 years as nurse).

Evidence of limited understanding of medical research was also found in the examples women gave of medical research studies. Three-fourths of HIV-positive women interviewed said they had previously heard of medical research, although $43 \%$ of these women described a preventive program or treatment regimen as an example of research, such as "Call-toAction," a medical care program for the prevention of mother-to-child transmission of HIV during labor and delivery. In fact, among those women who correctly named a medical research study conducted in Lilongwe, 55\% of their explanations either described only the therapeutic indirect benefits that accompanied the research or suggested the purpose was to improve the health of the enrolled participants; the experimental component of the research was not described.

\footnotetext{
${ }^{2}$ Participant's highest grade in school. Malawians attend 8 years of primary school (standards 1-8) and 4 years of secondary school (forms 1-4). "S" stands for "Standard" \& "F" stands for "Form."
} 
Focus group participants exhibited similar misconceptions about medical research. Referring to how the character in the focus group vignette, Abigail, would respond upon hearing about the conduct of research in Lilongwe on interventions to prevent mother-to-child transmission of HIV through breastfeeding, one focus group participant said, "The most important thing to Abigail is to give her baby breast milk so the baby grows healthy and does not have the disease like the one she has. She has heard the news of the study, and she is feeling happy because she knows it is one way of preventing her infant from getting HIV." In a different focus group discussion, one participant responded, "Abigail will not want her baby to get the disease, so she has to join the research." It was further explained that one purpose of the BAN study was to assess the safety and efficacy of medicines when used to prevent HIV transmission during breastfeeding. This provided participants with a more detailed definition of research and situated it within the context of an experiment. Responses changed regarding Abigail's reaction. For many participants, responses now reflected their enhanced understanding of the experimental nature of research. One focus group participant said, "Abigail will feel bad. When people hear that there is medical research, they expect to be told that we have found the medicine to cure you and not to be told that these are trials." Another participant said, "Because there are no medicines to prevent the spread of HIV during the time of breastfeeding, there is a need to do the research now. Abigail will understand this properly. She will have the mind to participate so that others, patients in the future, could benefit through the research. She knows there are no medicines given to prevent the transmission during breastfeeding." Yet another participant said, "Abigail is pleased because there is hope, though not certified or confirmed." Despite this enhanced understanding of the purpose of the BAN study among many focus group participants, several continued to believe that enrolled participants would obtain a therapeutic benefit from the study medication.

\section{UNDERSTANDING OF ABSTRACT RESEARCH CONCEPTS}

Randomization-"By chance" is a term commonly used to explain randomization in consent forms. To explain the concept of "chance" in Chichewa, translators can use either "mwayi," which is typically associated with the perception of luck, or "maere," which is associated with the perception of randomization. When asked how they understood the word "maere," $25 \%$ of HIV-positive women interviewed said they did not know its meaning; however, $40 \%$ appeared to have understood the implication of randomness, as evident in one woman's response: "this means that these people were grouped regardless of any factor" (married woman, age 20, F2). However, other definitions included "things are given to everyone" (married woman, age 27, S5), "people are secretly put into groups" (married woman, age 24, F1), and "something that has been done by magic" (married woman, age 20, F2). Also present in several responses by HIV-positive women was the belief that participants were allocated into study conditions based on their health status. As stated by one HIV-positive woman interviewed: "The grouping would be different depending on how sick or healthy the participant was. The sick participant would be getting more drugs than the other ones" (married woman, age 33, S7). Moreover, nurses believed that, in addition to low education among participants, difficulties in translating the meaning of English words and concepts into Chichewa, such as randomization, led to limited participant understanding of medical research.

Several HIV-positive women interviewed also believed that participants allocated to an active study condition were fortunate or lucky. Focus group participants also shared this perception, as suggested by one focus group participant: "It means if Abigail is lucky, she would be in the group receiving both medicine and supplement." 
Uncertainty-Uncertainty is an underlying concept of experimental research. When asked to explain how people talk about the uncertainties in life, many HIV-positive women interviewed described uncertainty as "something that happens unexpectedly" (married woman, age 24, F2). Several examples given of life events that happened unexpectedly were negative and mostly focused around illnesses and dying. Other women, however, focused on the unpredictability of life events: "Uncertainties are things people are unsure of. They just speculate. They just hope for things they do not know for certain" (married woman, age 22, S8). Women were also asked to discuss life events where they hoped for a good outcome but in the beginning the result was unknown. Several participants described small business or farming scenarios. For example, one woman said, "Sometimes you grow maize hoping to get a good yield but you are only sure of the yield after you get it" (married woman, age 36, S8). Another woman said, "You may start a business of selling foodstuffs with the hope of making profit, but you end up losing capital." (married woman, age 27, F2)

Risk and Benefits-Among HIV-positive women and research nurses, risks were most commonly described as side effects caused by medication, a perception also shared by focus group participants. Focus group participants also suggested that risks, such as side effects and other discomforts, would occur when women do not follow counseling advice or take the medicine as prescribed. Several HIV-positive women interviewed, on the other hand, recognized that risks were based on a loose definition of probabilities: "Risk means that different things happen to different people who take the drug. Some women will have a skin rash while others will not" (woman separated from husband, age 25, S1). Several women also associated the concept of risk with danger or suffering: "I think it is something which could cause harm to life" (married woman, age 27, F3). Risks beyond physical health were also mentioned. For example, focus group participants suggested that if the character in the vignette, Abigail, joins the BAN study, she could face problems from her husband if he is not informed of her participation or be stigmatized by her community. As explained by one focus group participant: "Abigail may also have problems in the community she is coming from if some find out about her participation in research."

With regard to benefits, HIV-positive mothers interviewed frequently suggested that one purpose of the antiretroviral intervention was to provide a maternal benefit. When asked about their expectations if they were to participate in the BAN study, $40 \%$ of women responded they would expect their lives to be prolonged or cured of HIV. One woman said, "I would live longer because of the medicine. I would possibly be cured completely" (married woman, age 20, S6). Another mother said, "To me this study is good because I believe it can help prolong life in mothers" (married woman, age 25, F4).

\section{USE OF CULTURALLY APPROPRIATE ANALOGIES TO EXPLAIN MEDICAL RESEARCH}

As mentioned earlier, understanding of medical research increased among many focus group participants when it was explained within the context of an experiment. In Chichewa, there is no word for "experiment," although the concept can be described through a series of words. In fact, the concept of an experiment is not new to Malawian culture. As explained by one focus group participant: "Medical research will not be a new phenomenon altogether. To borrow from our ancestors, when they wanted to find out what they did not know, there was a need for someone to give detailed information based on their experience and then research was done. For example, in the past, people just grew crops without fertilizer. Agricultural advisors came and told them that if you want to increase production, try fertilizer. People did research on this and saw that the fertilizer was useful and increased production. So research in medicine would not be a new concept to the people." 
Before they were asked specific questions about the appropriateness of using analogies, teachers suggested that "examples should be given about past experiences" (female teacher, 8 years teaching) to help contextualize research concepts. Repeatedly, teachers suggested the use of agriculture analogies. To explain the concept of randomization, one teacher said: "Explain to them by examples that in medical research it is just trials. For example, take two portions of land and apply fertilizer on one portion of land and the other none, but plant the same variety of maize. Then after harvesting you will be able to tell us which portion yielded more. This will tell us if the fertilizer worked or not. Same as in medical research, whereby it is just trials of the medicine and they are not sure if it will work or not. That is why it cannot be given to everyone" (female teacher, 10 years teaching). The same teacher provided an additional agriculture example to explain the purpose of research: "Medical research is a trial of medicine to see if they can work on certain diseases. For example, take maize. Try it on a portion of land to see if it can survive with little rain. If it survives, then people will be told that this type of maize seed can survive with little rain and therefore they can start planting it in times of little rain." A different teacher provided yet another agriculture example to contextualize the uncertainty of medical research: "When one grows crops in farming, you just grow crops without knowing the real outcome. Say in maize, during harvesting you cannot know how many bags you can yield until the end" (male teacher, 12 years teaching).

Teachers also mentioned other analogies to make consent information meaningful and understandable to participants. When asked how they would explain the purpose of the maternal study drug, many teachers suggested using "kalongolongo" as an analogy. "Kalongolongo" is an injection given to women during pregnancy to prevent their unborn babies from getting tetanus. As explained by one teacher: "Mothers don't take it because they are sick but to protect their babies" (female teacher, 13 years teaching). To make meaningful the concept of a future benefit as an overall purpose of medical research, teachers and nurses suggested a comparison between past research and the current availability of medicines for common illnesses: "Give examples of medicines which are being used now. Say that before doctors knew that this medicine cures TB, they had a research study. The medicine was tried on people in the past. After the research, the doctors knew that this drug could be given to TB patients because it was proven to cure TB. Now a lot of people are benefiting because of this research" (female teacher, 10 years teaching).

\section{Discussion of the Formative Findings}

Despite the fact that three-fourths of HIV-positive mothers interviewed indicated they had heard of medical research, awareness does not necessarily mean understanding. Although there are separate Chichewa terms for "medical research" and "medical care," many participants perceived them to be synonymous. Moreover, the word "research" and the concept of "experiment," which should be perceived similarly, appeared to have different meanings. This clearly demonstrates that more is needed to explain research than simply stating, "This is a research study." Compounding this problem is the fact that in sub-Saharan Africa, as well as in other areas, medical care for common illnesses is typically provided as an indirect benefit of research participation. For this reason, it is not surprising that most participants did not understand the experimental nature of medical research when the word "research" was used to describe a medical study.

Interestingly, similar findings from studies conducted in the United States also suggest that patients do not fully understand the purpose of medical research. For example, in their study among participants in cancer clinical trials, Joffe et al. (2001) reported that only $30 \%$ understood that the medicines provided in the trial had not been proven to be the "best treatment" for their cancer; the remaining participants were either unsure of the efficacy of 
the treatment or believed the treatment offered through the trial was the "best treatment." In another study, Sugarman et al. (1998) reported that cardiology and oncology patients perceived the terms "medical research" and "medical experiment" differently; a medical experiment was perceived to be riskier than medical research.

Given that HIV-positive women in our study perceived medical research to be similar to medical care, their belief that infants would be protected from HIV if they joined the research is understandable, albeit incorrect, as the benefit of the study's interventions is unknown at the beginning of a study. Moreover, because women suggested that one purpose of giving mothers medicines was to improve their own health, women did not fully understand the purpose of the BAN study. These results also provide evidence of therapeutic misconception (Appelbaum et al., 1982). Common among research participants in the U.S. and elsewhere (Dresser, 2002; Joffe et al., 2001; Lynöe et al., 2001), therapeutic misconception is the belief that research is carried out to benefit the people who are enrolled in the study.

In our study, other fundamental concepts of medical research, however, appeared to be better understood. For example, women varied in their understanding of uncertainty, but they shared the perception of the unknown when they discussed examples of uncertainty in their lives. Women's understanding of risk, while somewhat limited to the side effects of medication, encompassed some understanding of probability and included perceptions of potential harm. Understanding of randomization, on the other hand, varied among the participants. Not only were there multiple interpretations of the concept "by chance," but two Chichewa words with different meanings can be used to translate the term. The perception that participants are allocated into study conditions based on individual treatment needs, as found here and also in our earlier formative study, is not uncommon and has been reported in other research in the U.S. (Appelbaum et al., 1987).

\section{Development of the Context-Specific Consent Information}

In developing the consent information, we focused on describing the BAN study as an experiment, and reducing the therapeutic misconception (Appelbaum et al., 1987; NBAC, 2001). This included explaining the experimental nature of research at the beginning of the consent process, describing in general terms the reason for medical research and how its purpose separates it from medical care (Lidz \& Appelbaum, 2002), making explicit which procedures are medical care and which are experimental (NBAC, 2001), and explaining that medical research is conducted to generate knowledge to benefit people in the future, not the enrolled participants (Moreno, 2003).

Based on the analogies suggested by teachers, we chose to explain the experimental nature of a clinical trial by comparing it to a fertilizer trial. Previous studies in Africa have also used an agricultural example to explain research concepts (Préziosi et al., 1997). As the majority of Malawians have small plots of land to produce food for family consumption (Metzler, 2004), this was a salient example. Through this analogy, not only did we compare medical research to a familiar local experiment, but we also built upon the community's understanding of uncertainty by relating the unknown risks in medical research to uncertainties in farming, such as the amount of rain, uncontrollable weeds, and the potential for crop damage caused by the fertilizer (see Figure 3).

To make meaningful the overall purpose of research, we related it to the community's existing knowledge regarding a common medical treatment for malaria. Malaria is endemic to the area and it is commonly known that Fansidar is typically used for treatment. In the counseling cards, we explain that doctors are now able to provide Fansidar to people who 
have malaria because research in the past proved that Fansidar is a safe and effective treatment for malaria.

Equally as important, efforts were needed to reduce the perception that one purpose of the antiretroviral intervention for mothers was to treat their HIV disease. The purpose of the antiretrovirals for women was compared to the tetanus injection that is routinely given to pregnant women specifically to prevent neonatal tetanus, an analogy suggested by teachers and confirmed by nurses. Through this analogy, we explained that the purpose of the antiretrovirals provided to the mothers in the research was only for the sake of the infant, albeit unproven to prevent the transmission of HIV during breastfeeding.

Not only were the formative data used to identify appropriate analogies, they also significantly influenced how information was presented. U.S. protection of human subject regulations describe the type of information that must be provided in consent forms (DHHS, 1991); however, there is flexibility on how the required concepts are explained. Our formative data demonstrated areas where participants had limited, as well as sufficient, understanding of research concepts, and, therefore, we were able to expand upon the explanation of concepts for which understanding was limited and provide the additional information in a meaningful way. For example, an analogy was not used to explain the concept of randomization. Instead, from reviewing women's transcripts regarding their understanding or misunderstanding of randomization, and by using suggestions from teachers, nurses, and field investigators on how to explain randomization, we developed terminology to explain what randomization is and is not by using local terms and explanations (see Figure 4).

For another example, extra care was needed to explain the differences between procedures in the BAN study that were standard medical care and procedures that were experimental. To reduce the risk of HIV transmission during labor and delivery, the BAN study participants and their infants are offered single dose nevirapine (Guay et al., 1999) through Call-to-Action (now offered through the BAN study). Because our formative findings suggested that participants did not fully understand the differences between the purposes of the Call-to-Action program and the BAN study, we provided an expanded explanation, using the formative data to describe the differences. In addition, using antiretrovirals as prophylaxis against transmission also added a considerable amount of complexity to explaining the study, given the known therapeutic efficacy of these drugs. In the counseling cards, we acknowledged that the medicines used in the BAN study were not new, but, we stressed they had never been previously given to mothers or infants to prevent the spread of HIV during breastfeeding; thus, their efficacy when used in this "new way" was unknown.

Lastly, we used four other techniques to guide the development of the counseling cards. First, after an extensive discussion about research concepts and the BAN study, field investigators were given a brief outline of consent topics, and they were asked to use their own words and explanations to describe the consent information to some of the participants in the formative study. Their explanations were audiotaped, and the back-translations contributed to the explanation of several consent items (see Figure 4). Second, among many studies in Lilongwe, it was currently a customary practice for nurses to ask participants unstructured questions throughout the consent process to assess their understanding. Modified from recommendations that procedures should be developed to ensure participant understanding of consent information (NBAC, 2001) and based on formative research findings, we incorporated structured ques-tions throughout the counseling cards. We did this to ensure that participants understood the information as it was being explained and to increase the fidelity to the Malawian method of asking questions throughout the consent process when this method is used in practice. Third, we included many drawings in the 
counseling cards, as the use of illustrations facilitates learning when they provide textredundant information (Levie \& Lentz, 1982). Fourth, based on educational principles for using analogies, all analogies used in the context-specific text were described in detail before linking them with research concepts, and the main analogy—the fertilizer trial—was referred to throughout the text as a cue when new, similar concepts were described (Newby et al., 1995). For example, to introduce the concept of unknown risks, the text reads: "In the fertilizer trial we talked about earlier, farmers know that some conditions which are unforeseen at the beginning could happen that will keep the fertilizer from working as expected, such as weeds, dry spells, too much rain, pests and diseases, not so? This is also the case in medical research. Unforeseen conditions might arise which could prevent the medicines from working the way the people doing the research would like the medicines to work."

The counseling card text alone was field-tested with 13 women, and the counseling cards, complete with drawings, were field-tested with ten women and two nurses. Changes were made as appropriate.

\section{Development of the Drawings for the Counseling Cards}

Steps for developing and field-testing the drawings are illustrated in Figure 5. Storyboards describing each scene in the counseling card were created as the text was being developed. Scenes were informed by the formative data as well as the study procedures as outlined in the clinical trial protocol. Local actors and BAN study nurses arranged and appeared in each scene, as appropriate. Photographs were taken of each scene and given to a local artist, who reproduced them in color pencil while augmenting the actors' and nurses' faces to be personally unrecognizable. Each drawing was field-tested with nine women and three nurses. Changes were made as appropriate, and the drawings were field-tested again if modifications were significant. For example, the drawing in Figure 5 shows a woman at a follow-up examination. In the original picture, the infant was not included. During the field test, several women inquired about the woman's infant and noted that newborn infants are always with their mothers. After consulting with the BAN study nurses, we decided to include another nurse holding the infant in the corner of the room.

\section{Conclusion}

The counseling cards on informed consent incorporated four of the five strategies identified by Kreuter et al. (2003) for developing culturally appropriate interventions, and thus we followed the NBAC recommendation that consent information be disclosed through culturally appropriate and innovative ways. By using locally produced drawings, we incorporated a peripheral strategy. By involving Malawian field investigators in the design of the counseling cards, and through the conduct of formative research, we used a constituent strategy, at the same time following the NBAC recommendation for including the community in the design of consent information. We expanded the use of linguistic strategies by describing research concepts in Chichewa using words participants said in their interviews and explanations used by the field investigators, nurses, and teachers. By incorporating culturally appropriate analogies, a method linked to a theory for improving receptive learning, we included a sociocultural strategy in the development of our intervention. In addition, by including questions throughout the consent process, we adapted a process already used in Lilongwe for assessing participant understanding of the consent information during the consent process, which also follows the NBAC recommendation for developing measures to ensure participant understanding of consent information. 
To determine whether this approach would, in fact, improve participant understanding of research, we conducted an intervention trial to evaluate three informed consent approaches: (1) the enhanced consent form developed for the BAN study, (2) a consent approach that included only the context-specific information used in the counseling cards (no pictures), and (3) the counseling cards. We assessed participant understanding of research concepts (i.e. the eight basic elements of informed consent) and study procedures specific to the BAN study. The evaluation findings will be reported in detail elsewhere; however, in brief, the counseling cards were shown to significantly improve participant understanding of research concepts and study procedures compared to the enhanced consent form (Corneli et al., 2004). Supplementary data, such as level of participant attentiveness and nurse preferences, were also supportive of the use of counseling cards to obtain informed consent. Readers who wish to learn more about the evaluation may contact the corresponding author.

\section{Best Practices}

Although the context-specific content and drawings used in the counseling cards are not generalizable, we believe the steps outlined in this paper could be used to develop meaningful consent processes for other clinical trials conducted internationally and domestically, as well as for other types of research. The methods incorporated in this approach were based on research that has demonstrated the effectiveness of interventions that are informed by theory and formative research, that are culturally appropriate, or that use drawings with text simplification (Black, Siegel, Abel, \& Bentley, 2001; CreedKanashiro et al., 2000; Davis et al., 2003; Kelley \& Abraham, 2003; Miller, Edwards, Kissling, \& Sanville, 2002; Murphy et al., 1999).

When using this approach, investigators should modify the extent of informed consent preparedness activities based on the complexity of the research; not all research studies need an elaborate informed consent developmental process such as the one described here. For example, extensive preparations may be needed for a clinical trial with an investigational agent whereas fewer preparedness activities may be needed for survey data collection. That said, almost all studies would benefit from the collection of formative research on how best to explain the research using non-technical terms.

In summary, researchers wishing to develop a context-specific informed consent approach based on this research should incorporate:

- Peripheral strategies - such as the use of locally-produced and text-redundant drawings to support the verbal explanation of research concepts and study procedures

- Linguistic strategies—-such as modifying standard consent form text while keeping its overall original intent by framing it as it would be explained by potential participants, teachers, and local study staff

- Constituent strategies—such as involving local study staff when the consent forms are first developed and conducting formative research among potential participants and the broader community to determine areas of adequate research understanding and areas where additional explanation is needed

- Sociocultural strategies - such as the use of an educational theory or analogies to link new research information to previous knowledge about a commonlyunderstood phenomenon

Researchers should also ensure adequate time to collaborate with local counterparts to (1) plan, conduct, and analyze the formative research, and (2) develop and field-test the consent text informed by the formative research. Moreover, due to the inclusion of culturally- 
appropriate drawings, extra effort is needed in addition to developing the context-specific consent text. A local artist must be hired, and all individual drawings should be field-tested with potential participants and study staff. Further field-testing is needed once the contextspecific consent text and drawings are combined and transformed into counseling cards.

\title{
Research Agenda
}

The approach described here is only one of several potential methods that could be used to develop a meaningful informed consent process. Continued research is needed in this area. As a next step in empirical research on informed consent, counseling cards could become the standard approach, while an alternative approach is tested. An alternative approach worth further investigation would be the presentation of informed consent counseling cards over several consent sessions, as previous research has shown that multiple meetings to obtain consent has increased participant understanding of the consent information (Fitzgerald, Marotte, Verdier, Johnson, \& Pape, 2002). Additionally, as recommended by some researchers, alternative approaches for obtaining informed consent must be evaluated within the context of an actual clinical trial (Lavori, Sugarman, Hays, \& Feussner, 1999).

\section{Educational Implications}

This research demonstrates how to incorporate formative research and theory into the design of the informed consent process. Opportunities should be created for building capacity among local research staff in these areas. For example, a social scientist can partner will local staff to integrate a short qualitative data collection period into study preparedness activities. Likewise, social scientists can explore other educational theories that may enhance understanding of consent information and guide how theory can inform the consent process. By providing these opportunities, we hope that the steps outlined in this paper can be incorporated and improved upon when designing consent approaches for future research studies.

\section{Acknowledgments}

The authors present these data on the behalf of the BAN informed consent study working group. In addition to the authors, the working group includes the following individuals: J. Michael Bowling, James Chilima, Arnold Kadziponye, Kaja Finkler, David Jones, Peter Kazembe, Sibongile Mafuleka, Francis Martinson, Allan Steckler, and Cynthia Zulu. This group was involved in several aspects of the study, including designing the counseling cards and planning and implementing the study.

We thank Drs. Nancy Kass and Susanne Maman for their creative suggestions when this research was conceptualized and Dr. Ron Strauss for his thoughtful comments on the draft manuscript. We also would like to thank the field investigators for their dedication and hard work and the community members who participated in the study. The drawings were created by the Malawian artist Nyangu Andrew Chodola.

\begin{abstract}
This work was funded in part by a 2002 developmental grant from the University of North Carolina at Chapel Hill Center for AIDS Research (CFAR); the Prevention Research Centers Special Interest Project SIP 13-01 U48CCU409660-09 and SIP 26-04 U48-DP000059-01, Centers for Disease Control and Prevention; supported by the NIAID P30-AI50410 UNC Center for AIDS Research; DHHS/NIH/FIC 2-D43 Tw01039-06 AIDS International Training and Research Program; Elizabeth Glaser Pediatric AIDS Foundation Call to Action Award and International Leadership Award, UNICEF, World Food Programme, GlaxoSmithKline, Boehringer-Ingelheim, Roche Pharmaceuticals, and BristolMyersSquibb Company and the Ministry of Health and Population of Malawi.
\end{abstract}

\section{Biography}

Amy Corneli is currently an Associate Scientist II at Family Health International. This research was conducted as part of her dissertation research at the University of North Carolina at Chapel Hill. Her research focuses on international research ethics, specifically on informed consent and issues related to disclosure and assent among youth participating in 
HIV-related research. She also collaborates on sociobehavioral preparedness and community activities in support of HIV prevention clinical trials. Co-authors on this manuscript include Malawian UNC Project Staff and field investigators who contributed to the design of the counseling cards and to the planning and implementation of the research (Agnes Moses, Jacqueline Nkhoma, and Lyson Tenthani), several professors on Dr. Corneli's dissertation committee who contributed significantly to this phase of the overall research (Margaret E. Bentley, James R. Sorenson, Gail E. Henderson, and Charles van der Horst), and members of the CDC BAN study team who were actively involved in the preparation, analysis, and interpretation of the sub-studies conducted on informed consent for the BAN clinical trial (Yusuf Ahmed, Charles M. Heilig, and Denise J. Jamieson).

\section{References}

Advisory Committee on Human Radiation Experiments (ACHRE). Final report of the Advisory Committee on Human Radiation Experiments. Washington, DC: U.S. Government Printing Office; 1995. (Stock \#: 061-000-00-848-9.)

Agre P, Campbell FA, Goldman BD, Boccia ML, Kass N, McCullough L, Mintz J, Rapkin B, Sugarman J, Sorenson J, Wirshing D. Improving informed consent: the medium is not the message. IRB, Supple. 2003; 25(5):S11-S19.

Appelbaum PS, Roth LH, Lidz C. The therapeutic misconception: informed consent in psychiatric research. International Journal of Law \& Psychiatry. 1982; 5(3-4):319-329. [PubMed: 6135666]

Appelbaum PS, Roth LH, Lidz CW, Benson P, Winslade W. False hopes and best data: Consent to research \& the therapeutic misconception. The Hastings Center Report. 1987; 17(2):20-24. [PubMed: 3294743]

Ausubel, DP. The psychology of meaningful verbal learning. New York, NY: Grune \& Stratton, Inc.; 1963.

Ausubel, DP. Educational psychology: A cognitive view. New York, NY: Holt, Rinehart, \& Winston, Inc.; 1968.

Ausubel, DP. The acquisition \& retention of knowledge: A cognitive view. Dordrecht, The Netherl\&s: Kluwer Academic Publishers; 2000.

Bentley ME, Pelto GH, Straus WL, Schumann DA, Adegbola C, de la Pena E, Oni GA, Brown KH, Huffman SL. Rapid ethnographic assessment: Applications in a diarrhea management program. Social Science \& Medicine. 1988; 27:107-116. [PubMed: 3212501]

Birbili M. Translating from one language to another. Social Research Update. 2000; 31:1-9.

Corneli AL, Piwoz EG, Bentley ME, Moses A, Nkhoma JR, Carlton Tohill B, Adair L, Mtimuni B, Ahmed Y, Duerr A, Kazembe P, van der Horst C. the UNC Project BAN Study Team. Involving communities in the design of clinical trial protocols: The BAN Study in Lilongwe, Malawi. Contemporary Clinical Trials. 2007; 28:59-67. [PubMed: 17000137]

Corneli, A.; Sorenson, J.; Nkhoma, J.; Moses, A.; Zulu, C.; Chilima, J.; Bowling, M.; Henderson, G.; Bentley, M.; Martinson, F.; Jones, D.; Ahmed, Y.; Heilig, C.; Kazembe, P.; Jamieson, D.; van der Horst, C. Evaluation of Three Informed Consent Processes for a Clinical Trial on the Prevention of Mother-to-Child Transmission of HIV through Breastfeeding in Lilongwe, Malawi. Oral presentation at XV International AIDS Conference in Bangkok; Thailand. 2004 July.

Cortes LM, Gittelsohn J, Alfred J, Palafox NA. Formative research to inform intervention development for diabetes prevention in the Republic of the Marshall Islands. Health Education \& Behavior. 2001; 28:696-715. [PubMed: 11720273]

Creed-Kanashiro H, Oré B, Scurrah M, Gil A, Penny M. Conducting research in developing countries: Experiences of the informed consent process from community studies in Peru. Journal of Nutrition. 2005; 135(4):925-928. [PubMed: 15795463]

Creed-Kanashiro HM, Bartolini RM, Fukumoto MN, Uribe TG, Robert RC, Bentley ME. Formative research to develop a nutrition education intervention to improve dietary iron intake among women \& adolescent girls through community kitchens in Lima, Peru. Journal of Nutrition. 2003; 13311 Suppl. 2:3987S-3991S. [PubMed: 14672300] 
Daugherty C, Ratain MJ, Grochowski E, Stocking C, Kodish E, Mick R, Siegler M. Perceptions of cancer patients \& their physicians involved in phase I trials. Journal of Clinical Oncology. 1995; 13:1062-1072. [PubMed: 7738612]

Department of Health \& Human Services (DHHS). 45 Code of Federal Regulations 46. Federal Register. 1991 June 18.56:28012.

Dresser R. The ubiquity \& utility of the therapeutic misconception. Social Philosophy \& Policy. 2002; 19:271-294. [PubMed: 12678090]

Dunn LB, Jeste DV. Enhancing informed consent for research and treatment. Neuropsychopharmacology. 2001; 24(6):595-607. [PubMed: 11331139]

Edwards SJL, Lilford RJ, Thornton J, Hewison J. Informed consent for clinical trials: in search of the "best" method. Social Science \& Medicine. 1998; 47(11):1825-1840. [PubMed: 9877351]

Ekouevi KD, Becquet R, Viho I, Bequet L, Dabis F, Leroy V. ANRS1201/1202 Ditrame Plus Study Group. AIDS. 2004; 18(10):1486-1488. [PubMed: 15199334]

Flory J, Emanuel E. Interventiosn to improve research participants' understanding in informed consent for research. JAMA. 2004; 292(13):1593-1601. [PubMed: 15467062]

Fitzgerald DW, Marotte C, Verdier RI, Johnson WD Jr, Pape JW. Comprehension during informed consent in a less-developed country. Lancet. 2002; 360:1301-1302. [PubMed: 12414207]

Gaillard P, Fowler MG, Dabis F, Coovadia H, van der Horst C, van Rompay K, Ruff A, Taha T, Thomas T, de Vincenzi I, Newell ML. the Ghent IAS Working Group on HIV in Women \& Children. Use of anti-retroviral drugs to prevent HIV-1 transmission through breastfeeding: From animal studies to r\&omized clinical trials. Journal of Acquired Immune Deficiency Syndromes. 2004; 35(2):178-187. [PubMed: 14722452]

Guay LA, Musoke P, Fleming T, Bagenda D, Allen M, Nakabiito C, Sherman J, Bakaki P, Ducar C, Deseyve M, Emel L, Mirochnick M, Fowler MG, Mofenson L, Miotti P, Dransfield K, Bray D, Mmiro F, Jackson JB. Intrapartum \& neonatal single-dose nevirapine compared with zidovudine for prevention of mother-to-child transmission of HIV-1 in Kampala, Uganda: HIVNET 012 randomized trial. Lancet. 1999; 354:795-802. [PubMed: 10485720]

Henley L, Benatar SR, Robertson BA, Ensink K. Informed consent: A survey of doctors' practices in South Africa. South African Medical Journal. 1995; 85:1273-1278. [PubMed: 8600583]

Hughes R, Huby M. The application of vignettes in social and nursing research. Journal of Advanced Nursing. 2002; 37:382-386. [PubMed: 11872108]

Jamieson DJ, O'Sullivan M, Maupin R, Cohen M, Webber MP, Nesheim S, Lampe M, Garcia P, Lindsay M, Bulterys M. The challenges of informed consent for rapid HIV testing in labor. Journal of Women's Health. 2003; 12(9):889-895.

Jimison HB, Sher PP, Appleyard R, LeVernois Y. The use of multimedia in the informed consent process. Journal of the American Medical Informatics Association. 1998; 5:245-256. [PubMed: 9609494]

Joffe S, Cook EF, Clearly PD, Clark JW, Weeks JC. Quality of informed consent in cancer clinical trials: A cross-sectional survey. Lancet. 2001; 358:1772-1777. [PubMed: 11734235]

Kass, P.; Hyder, AA. Ethical and policy issues in international research: Clinical trials in developing countries, Volume II: Commissioned papers and staff analysis. Bethesda, MD: National Bioethics Advisory Commission; 2001. Attitudes \& experiences of U.S. \& developing country investigators regarding U.S. human subject regulations; p. B1-B158.

Kreuter MW, Lukwago SN, Bucholtz RD, Clark EM, S\&ers-Thompson V. Achieving cultural appropriateness in health promotion programs: Targeted \& tailored approaches. Health Education \& Behavior. 2003; 30:133-146. [PubMed: 12693519]

Leach A, Hilton S, Greenwood BM, Manneh E, Dibba B, Wilkins A, Mulholl EK. An evaluation of the informed consent procedure used during a trial of a Haemophilus influenzae type B conjugate vaccine undertaken in The Gambia, West Africa. Social Science \& Medicine. 1999; 48:139-148. [PubMed: 10048773]

Levie WH, Lentz R. Effects of text illustrations: A review of research. Educational Communication \& Technology Journal. 1982; 30:195-232.

Lidz CW, Appelbaum PS. The therapeutic misconception: Problems \& solutions. Medical Care. 2002; 409 Suppl.:V55-V63. [PubMed: 12226586] 
Lynöe N, Hyder Z, Chowdhury M, Ekström L. Obtaining informed consent in Bangladesh. New England Journal of Medicine. 2001; 344:460-461.

Marshall, PA. Ethical \& policy issues in international research: Clinical trials in developing countries, Volume II: Commissioned papers \& staff analysis. Bethesda, MD: National Bioethics Advisory Commission; 2001. The relevance of culture for informed consent in U.S. funded international health research; p. C1-C38.

McLellan E, MacQueen K, Neidig J. Beyond the qualitative interview: Data preparation \& transcription. Field Methods. 2003; 15:63-84.

Metzler, JD. Malawi—World Book Online Reference Center. World Book, Inc.; 2004 April 10. Retrieved April 10, 2004, from http://www.aolsvc.worldbook.aol.com/wb/Article?id=ar339980.

Miles, MB.; Huberman, AM. Qualitative data analysis: An expanded Sourcebook. 2nd ed.. Thousand Oaks, CA: Sage Publications; 1994.

Molyneux CS, Peshu N, Marsh K. Understanding of informed consent in a low-income setting: three case studies from the Kenyan Coast. Social Science \& Medicine. 2004; 59(12):2547-2559. [PubMed: 15474208]

Moreno JD. Abandon all hope? The therapeutic misconception \& informed consent. Cancer Investigation. 2003; 21:481-482. [PubMed: 12901293]

Murphy DA, O'Keefe ZH, Kaufman AH. Improving comprehension and recall of information for an HIV vaccine trial among women at risk for HIV: Reading level simplification \& inclusion of pictures to illustrate key concepts. AIDS Education \& Prevention. 1999; 11:389-399. [PubMed: 10555623]

National Bioethics Advisory Commission (NBAC). Volume I: Report \& Recommendations of the National Bioethics Advisory Commission. Bethesda, MD: National Bioethics Advisory Commission; 2001. Report on clinical trials research in developing countries.

Newby TJ, Ertmer PA, Stepich DA. Instructional analogies and the learning of concepts. Educational Technology Research \& Development. 1995; 43:5-18.

Nuremberg Code. Trials of War Criminals Before the Nuremberg Military Tribunals under Control Counsel Law. Washington, DC: U.S. Government Printing Office; 1949. p. 181-182.No. 10

Pace C, Emanuel EJ, Chuenyam T, Duncombe C, Bebchuk JD, Wendler D, Tavel JA, McNay LA, Phanuphak P, Forster HP, Grady C. for the ESPRIT group. The quality of informed consent in a clinical research study in Thailand. IRB. 2005; 27(1):9-17. [PubMed: 15835065]

Patton, MQ. Qualitative evaluation and research methods. 3rd ed.. Newbury Park, CA: Sage Publications; 2002.

Peduzzi P, Guarino P, Donta ST, Engle CC Jr, Clauw DJ, Feussner JR. Research on informed consent: investigator-developed versus focus group-developed consent documents, a VA cooperative study. Controlled Clinical Trials. 2002; 23:184-197. [PubMed: 11943447]

Préziosi MP, Yam A, Ndiaye M, Simaga A, Simondon F, Wassilak SG. Practical experiences in obtaining informed consent for a vaccine trial in rural Africa. New England Journal of Medicine. 1997; 336:370-373. [PubMed: 9011793]

Reigeluth CM. Meaningfulness \& instruction: Relating what is being learned to what a student knows. Instructional Science. 1983; 12:197-218.

Riecken HW, Ravich R. Informed consent to bio-medical research in Veterans Administration Hospitals. JAMA. 1982; 248:344-348. [PubMed: 7045434]

S\&elowski M. Qualitative analysis: What it is \& how to begin. Research in Nursing \& Health. 1995; 18:371-375. [PubMed: 7624531]

Scrimshaw, NS.; Gleason, GR. Rapid assessment procedures: Qualitative methodologies for planning $\&$ evaluation of health related programmes. Boston, MA: International Nutrition Foundation for Developing Countries (INFDC); 1992.

Sugarman J, Kass NE, Goodman SN, Perentesis P, Fern\&es P, Faden RR. What patients say about medical research. IRB. 1998; 20(4):1-7.

van der Horst C, Fiscus S, Piwoz E, Corneli A, Moses A, Jones D, Adair L, Bentley M, Hoffman I, Kashuba A, Shugars D, Bangdiwala K, Tien H. Prevention of mother to infant transmission of HIV through breastfeeding \& reduction of morbidity \& mortality of the breastfeeding mothers: A study in Malawi. Antiviral Therapy. 2003; 81 Suppl.:S477. 
Woodsong C, Abdool Karim Q. A model designed to enhance informed consent: Experiences from the HIV prevention trials network. American Journal of Public Health. 2005; 5(3):412-419. [PubMed: 15727968]

Woodsong, C.; Abdool Karim, Q.; Coletti, A. Improving informed consent in HIV/AIDS research: A conceptual framework \& support materials. Thailand: Poster presentation at XV International AIDS Conference in Bangkok; 2004 July.

World Health Organization \& Council for International Organizations of Medical Sciences (WHO/ CIOMS). International ethical guidelines for biomedical research involving human subjects. Geneva: WHO; 2002.

World Medical Association (WMA). Declaration of Helsinki: Ethical principles for medical research involving human subjects, as amended by the 52nd WMA General Assembly. Scotland: Edinburgh; 2000. October 2000. 


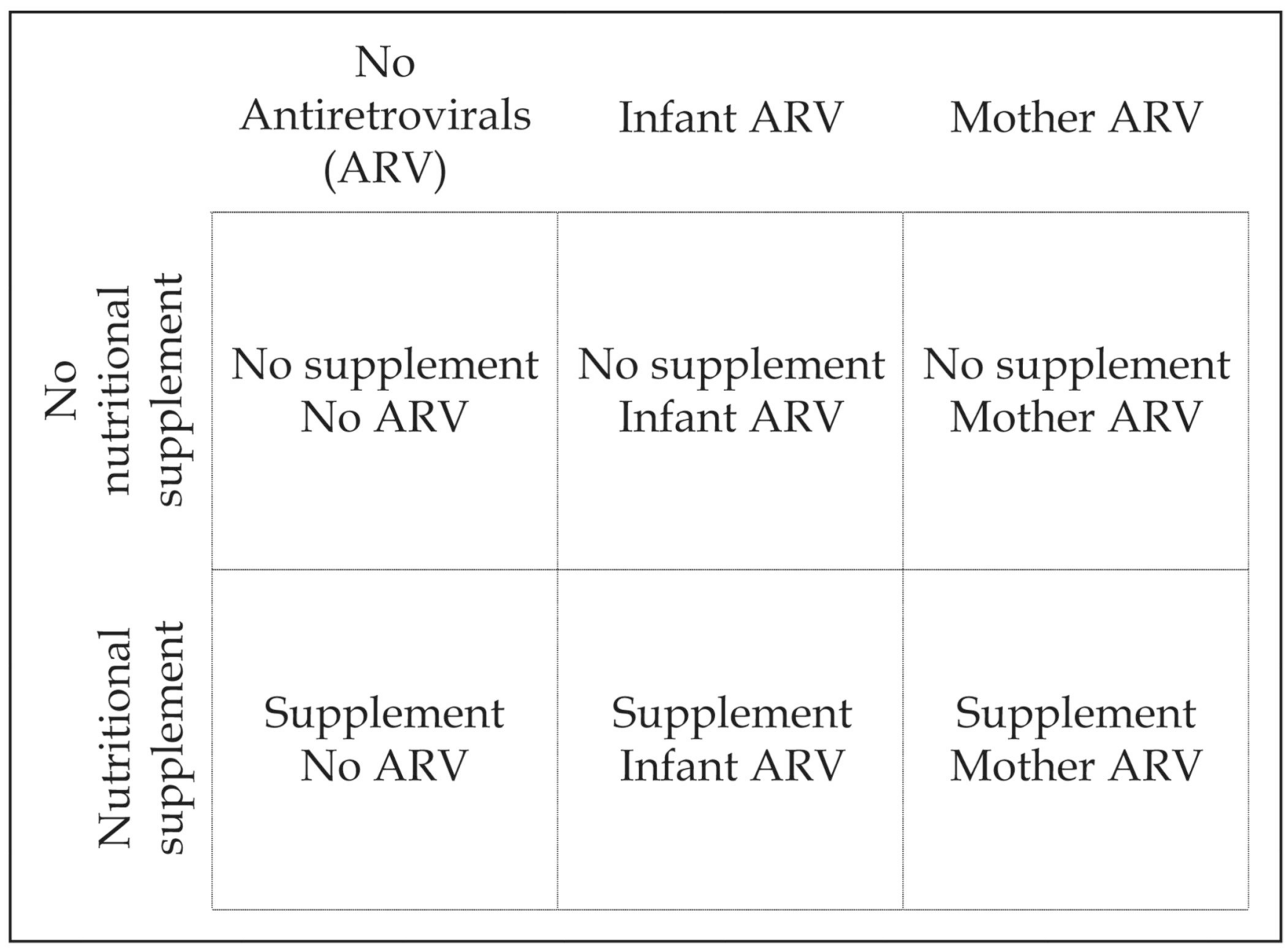

FIG. 1.

BAN study design. 
Abigail is a 22-year-old woman who lives in Lilongwe. She lives in a two-room home with her husband and her 2-year-old son. She is about 7 months pregnant with her second child. She spends the day taking care of the house and her son. Her husband does casual labor so he works off and on when he's able to find small jobs.

Abigail hasn't been feeling well lately, and because she thinks she might not be her husband's first girlfriend, she decides to get a HIV test. Abigail gets the test and she finds out that she is HIV positive. She knows she and her baby can get medications at birth to prevent the spread of HIV during labor and delivery. When she is at the clinic, she hears about a medical research study that might take place in Lilongwe that is looking at ways to prevent mother-to-child-transmission of HIV through breastfeeding. She wants to breastfeed her new baby.

Sample follow-up questions:

- What do you think Abigail will do next? What will influence her choice?

- How do you think Abigail feels about medical research in general?

FIG. 2.

Excerpt from the vignette used in the focus group discussions. 

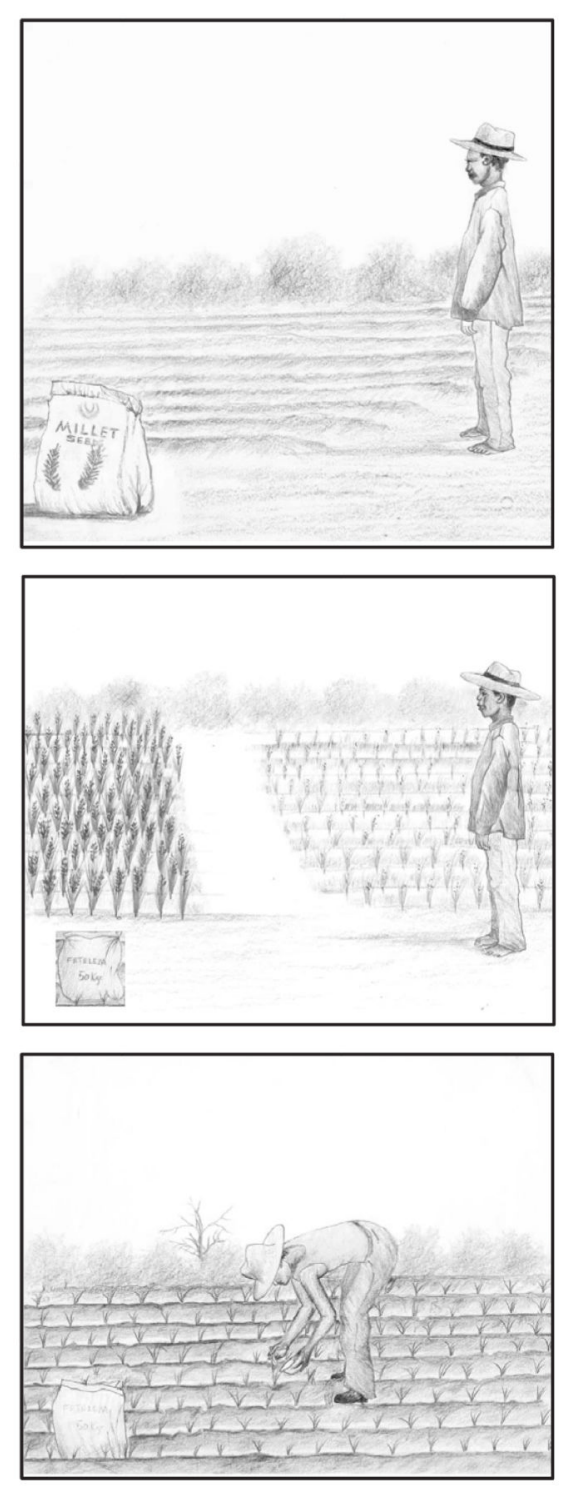

Let us say there is a farmer in Lilongwe who grows maize. The farmer now wants to grow millet because his relatives in the south grow this crop, but he is unsure of what fertilizer to use. So he does an experiment to find out.

The farmer has two plots of land that have been seeded. He and his wife add the fertilizer to one of his plots. He does not add the fertilizer to his other plot. The reason he adds the fertilizer to only one of his plots is so he can compare the yield of millet between the plot with the fertilizer and the plot that did not get any fertilizer.

The farmer hopes the fertilizer that has increased his yield of maize in the past will also increase his yield of millet now. But, when he starts the experiment, he is uncertain if the fertilizer will work for growing millet. It is possible that the fertilizer will burn his crop or damage the soil. Other factors might also limit the amount of yield such as if the rains do not come or there are too many weeds. Even though the farmer is uncertain of the end result, he wants to test the fertilizer to see if it will increase his yield of millet.

At the end of the fertilizer trial, if the plot with the fertilizer yields less millet than the plot without fertilizer, the farmer knows that the fertilizer did not work for his soil and crop. If the plot with the fertilizer yields more millet, he has proven that the fertilizer works and is not harmful to his specific crop.

He will tell other farmers that this fertilizer works for this crop and soil so they too can benefit from his experiment.

Similar types of experiments are done in medical research....

FIG. 3.

An abbreviated description from the counseling cards regarding an analogy about medical research. 


\section{Explanation}

"Mothers are not put into groups based on their health status or their infant's health status ${ }^{\mathrm{a}}$. Nurses will not look at a mother and say that she looks healthy or sick so she needs to be in a certain group ${ }^{b}$. All mothers and infants have the same health status so they must be divided equally among all six groups ${ }^{\mathrm{a}}$. Mothers cannot choose their group. Mothers are placed into different groups so there is room for comparison ${ }^{\mathrm{c}}$, just like is done in fertilizer trials ${ }^{\mathrm{d}}$. Mothers and their infants are put into the different groups by chance representing randomization. Mothers are not put into groups by chance representing luck ${ }^{\mathrm{e}} . .$. "

\section{Description}

${ }^{a}$ Based on a misperception shared by several mothers.

${ }^{b}$ Text from the back-translation of a field investigator's explanation of randomization.

${ }^{c}$ Text taken from a teacher's suggested explanation of randomization.

${ }^{d}$ A comparison between the need for different study groups in medical research and the need for different plots in a fertilizer trial, a concept discussed at the beginning of the counseling cards.

${ }^{e}$ A statement to clarify the differences between the two Chichewa words for chance.

FIG. 4.

An example of how formative data informed part of the explanation of randomization. 

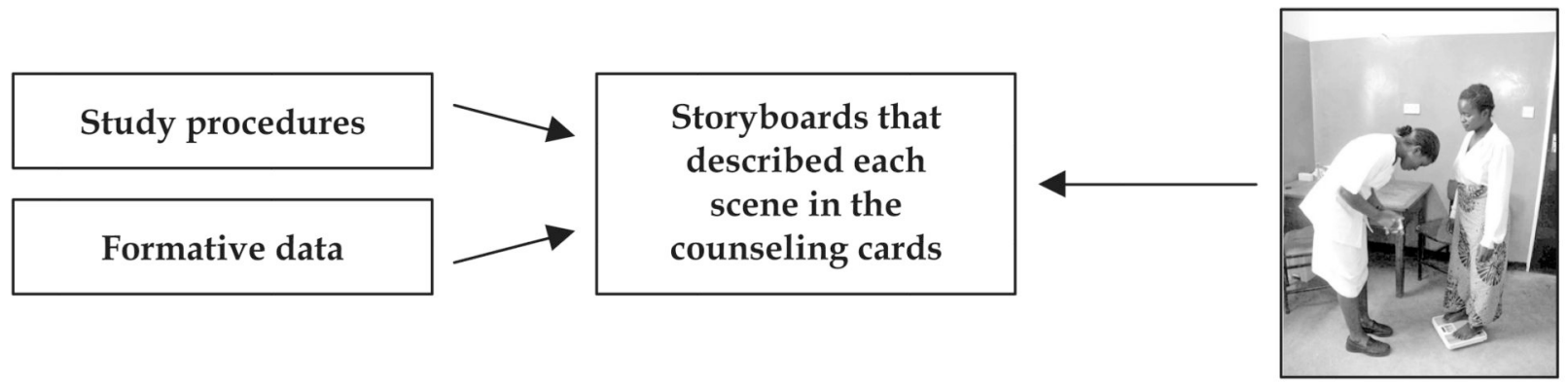

Photographs taken of local actors \&

BAN study nurses

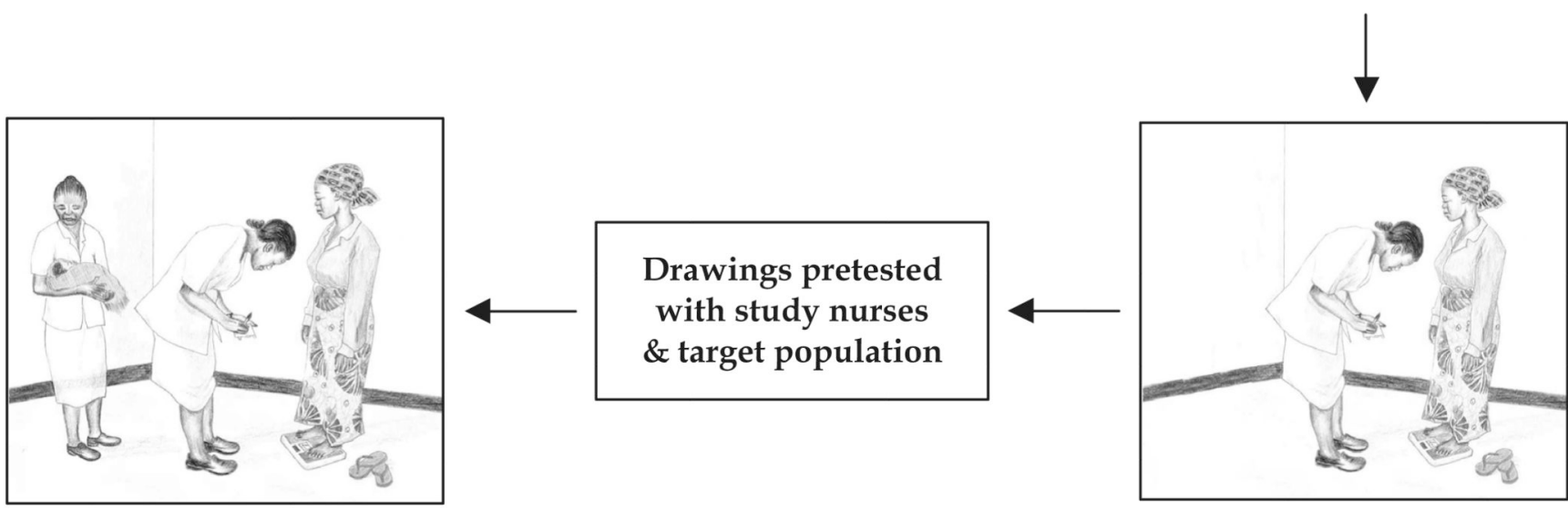

Final drawings

Original drawings created by local artist

FIG. 5.

Developmental process for draw ings included in the counseling cards. 